\title{
Green Chemistry Education among Senior High School Chemistry Teachers: Knowledge, Perceptions, and Level of Integration
}

\author{
Dinna Carangue ${ }^{1}$, Immar Jun Geverola ${ }^{2}$, Marijul Jovero ${ }^{3}$, Eva Niña Lopez ${ }^{4 *}$, Aylene Pizaña ${ }^{5}$, \\ Josephine Salmo ${ }^{6}$, Joysyl Silvosa ${ }^{7}$, and Jay Picardal ${ }^{8}$ \\ 'Don Carlos A. Gothong Memorial National High School, Cebu City, Philippines, https://orcid.org/0000-0003-4245-8514 \\ ${ }^{2}$ Alaska Night High School, Cebu City, Philippines, https://orcid.org/0000-0002-7333-8569 \\ ${ }^{3}$ Surigao State College of Technology, Surigao City, Philippines, https://orcid.org/0000-0001-7866-8797 \\ ${ }^{4}$ Western Philippines University, Palawan, Philippines, https://orcid.org/0000-0002-1598-102X \\ ${ }^{5}$ Western Philippines University, Palawan, Philippines, https://orcid.org/0000-0001-5864-5723 \\ ${ }^{6}$ Western Philippines University, Palawan, Philippines, https://orcid.org/0000-0003-4037-3250 \\ ${ }^{7}$ Taft National High School, Surigao City, Philippines, https://orcid.org/0000-0001-6439-5812 \\ ${ }^{8}$ Cebu Normal University, Cebu City, Philippines, https://orcid.org/0000-0001-5986-0556 \\ *Email Correspondence: evaninalopez@gmail.com
}

\begin{abstract}
Green Chemistry (GC) integration in environmental education has improved understanding of managing pollutants and their impacts. However, the extent of integration in the science curriculum is not widely known in the Philippines. In this convergent mixedmethod design, the researchers determined the SHS Chemistry teachers' $(n=30)$ knowledge, perceptions, GC integration in Chemistry topics, and challenges in teaching Green Chemistry Education (GCE). Complementary quantitative and qualitative results showed valid and reliable findings, claiming that teachers have limited preconceived knowledge on GCE but perceived it as an essential part of the teaching-learning process. Awareness of chemical hazards and their impacts on the environment is often demonstrated but rarely elaborated during discussions in Chemistry classes. Problems encountered in teaching GCE were also identified. A moderate positive correlation between the teachers' knowledge and their GC perception was observed. However, no significant relationship was found when the teachers' knowledge and perception were correlated to GC integration.
\end{abstract}

Keywords: Green Chemistry Education, teachers' perception, level of knowledge, extent of integration

\subsection{Introduction}

Green Chemistry (GC) is an area of chemistry focused on designing chemical products and processes that reduce hazardous substances (Anastas \& Eghbali, 2010). Thus, reducing the chemical-related impact on human health and contamination of the environment (Zuin et al.,
2021) is important. GC also searches for alternative, innovative (Zuin et al., 2021), and environmentalfriendly reaction media (Anastas \& Eghbali, 2010), replacement of toxic solvents, and the application of various "greener" approaches that embody the 12 major principles of GC (Anastas \& Warner, 1998). GC is neither an independent subfield nor a 
newly-created branch of chemistry, and it is rather considered a chemical philosophy, focusing on contemporary approaches of doing and applying chemistry to various fields of endeavor (Santos \& Guidote, 2015).

Since the creation of its guiding principles and theories (about 30 years ago) and the offering of Introduction to Green Chemistry course at Carnegie Mellon University (Collins, 1995), research publications on the topic increased, and pedagogical strategies were observed to integrate GC in the teaching of chemistry among higher education institutions in North America (Andraos \& Dicks, 2012). Green Chemistry Education (GCE) eventually became a new approach in education (Kitchens et al., 2006; Zuin et al., 2021) and a classroom platform to discuss the environmental conservation dimension of sustainable development. However, these initiatives were only evident for courses leading to the completion of degree programs intended for chemists, chemical engineers, and chemical technologists ("Twelve More Green Chemistry", 2001) who are likely to practice their profession in industries and chemical processing companies. Other Western countries have also adopted teaching GCE following the curriculum integration in US-based chemistry education (Aubrecht et al., 2019). Germany was the pioneer in integrating GCE in the undergraduate curriculum (Wissinger et al., 2020; Zuin et al., 2021) and eventually in the high school curriculum (Linkwitz \& Eilks, 2020). However, the trend is rarely observed in some developing countries like Nigeria and Indonesia (Auliah \& Mulyadi, 2018; Owoyemi \& Adesina, 2020) due to the relatively inadequate content knowledge and awareness on GCE among Science teachers (Kitchens et al., 2006; Cann \& Dickneider, 2004; Auliah \& Mulyadi,
2018), inevitable consequences of the crowded curriculum where contact time is reduced as well as limited instructional materials to support content understanding (Haack, 2016) and poor contextualization of Science topics (TabotaboPicardal \& Paño, 2018; Nersesian et al., 2019).

In the Philippines, at least two (2) publications delved on GC, namely: Santos and Guidote (2015) on designing a "greenified" experiment and Paderes (2018) on GC perspective among the Senior High School (SHS) students of Science, Technology Engineering and Mathematics (STEM) Strand. Santos and Guidote (2015) proposed an innovative way of finding alternative feedstock or starting materials to produce a chemical substance (i.e., using guava leaves to produce tannin instead of carcinogenic tannic acid). Such experiments optimized the iron (III) tannate production using organic materials (from guava) that employ GC principles: less hazardous chemical synthesis, renewable feedstock use, and safer chemicals for accident prevention. Meanwhile, Paderes (2018) investigated the potential relationships of the various STEM SHS students' attributes (sociodemographics, attitude, and practices) towards GC as a whole. This latter study noted that students' membership in subject-related organizations and their corresponding involvement in environmental activities are positively correlated to their level of knowledge in GC. Such correlation suggests the important role of school-based activities in underscoring the fundamental principles of GC when applied to their daily lives. However, this paper did not highlight what specific GC principles were taught and learned by students and how these principles contribute to students' level of knowledge in both content and practical applications of chemistry concepts. 
The initial findings from these two publications increased the awareness of the stakeholders (i.e., students under the basic education curriculum) on GC education. However, these localized findings may not reflect the trends at the regional or national scale. Considering that students are not the only stakeholders of Science education, much remains to be explored to understand completely the interplay of factors behind the lack of integration of GC in the basic education curriculum. Similarly, the various approaches that Filipino teachers may use to facilitate the understanding of content and the application of GC principles in learning chemistry are still unexplored. Therefore, further investigations and inquiries, particularly those related to perceptions, misconceptions, and challenges encountered in teaching and integrating GC principles into the present science curriculum are imperative and necessary. To address these knowledge gaps in GCE in the Philippines, three fundamental questions are asked: What are the perceptions of the Science teachers on GC in the country?; Are there any potential relationships between our SHS Chemistry teachers' background knowledge and the extent of GCE integration?; and finally, What challenges are encountered by the SHS Chemistry teachers in the teaching of GC?

\subsection{Methods}

\section{Research Design}

A mixed-method approach using convergent parallel design was used in this study. Here, the researchers simultaneously conducted both the quantitative and qualitative phases parallel to each other, weighed the method equally, examined the findings of each phase, and interpreted the results (Creswell \& Pablo-Clark, 2011). Figure 1 shows how the mixed method approach proceeded in the study.

\section{Research Participants and Sampling Technique}

Purposive and criterion-based sampling techniques were employed in this study due to the limited number of SHS institutions offering the STEM strand and the increasing COVID-19 cases in the Philippines. The researchers ensured that the participants were qualified in the inclusion criteria formulated: public and private SHS chemistry teachers who have at least a two-year experience in teaching chemistry and are willing to engage in the survey and interview process. Out of the 65 SHS Chemistry teachers from Luzon, Visayas, and Mindanao who were invited, 30, responded. However, among these 30 participants, only 24 teachers were included in the qualitative interview as it already reached the data saturation point and no new themes emerged.

\section{Data Gathering Procedures and Ethical Considerations}

A certificate from the Research Ethics Committee of Cebu Normal University was secured before the conduct of the study. After the approval, the researchers sent an invitation, a consent form that indicates voluntary participation, and provision to withdraw from the study at any time. Together with that form is the research outline with a copy of the participant's rights, and confidentiality protection. All these were sent to the teacher participants via email. For confidentiality and anonymity, a code was assigned to each participant. The hard copies of the data gathered from the teachers were kept in locked file cabinets while the soft ones were stored in password-protected computers. 


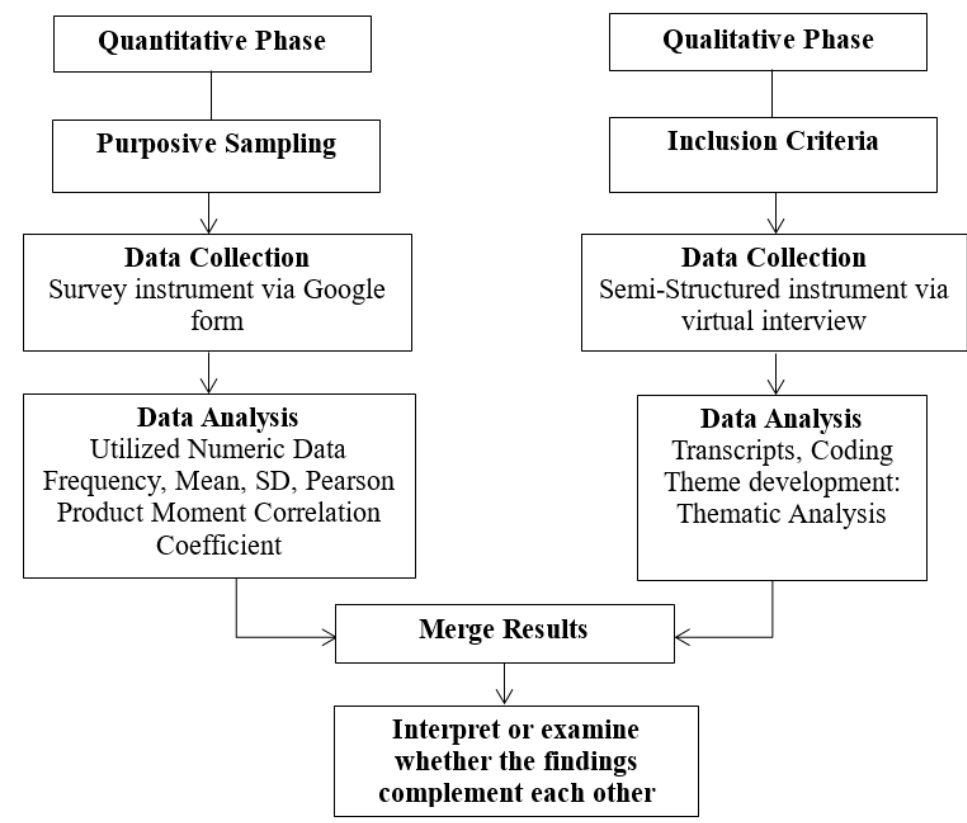

Figure 1. Convergent parallel mixed-methods were used to determine the level of knowledge, perception, the extent of integration, and problems encountered in GCE

(Creswell \& Pablo-Clark, 2011).

\section{Data Gathering Procedures and Ethical Considerations}

A certificate from the Research Ethics Committee of Cebu Normal University was secured before the conduct of the study. After the approval, the researchers sent an invitation, a consent form that indicates voluntary participation, and provision to withdraw from the study at any time. Together with that form is the research outline with a copy of the participant's rights, and confidentiality protection. All these were sent to the teacher participants via email. For confidentiality and anonymity, a code was assigned to each participant. The hard copies of the data gathered from the teachers were kept in locked file cabinets while the soft ones were stored in password-protected computers.

\section{Quantitative Data Collection and Analysis}

An instrument adapted from the American Chemical Society Green Chemistry (ACSGC) High School Test Questionnaire was used to measure the GC knowledge level of participants. All questions were identical to the original ACSGC instrument except that only 25 items consisted of questions related to the GC aim, principles, tools, concepts, and application, and environmental issues were considered. A MacKellar et al. (2020) survey questionnaire was also adapted to determine the perception of the importance of GC, and rated in a three-point Likert scale ranging from "not important" to "essential." In integrating GC in teaching General Chemistry, a four-point Likert scale ranging from "not demonstrated" to "always demonstrated" was utilized. In addition, topics 
in the SHS General Chemistry Curriculum were identified. Challenges of GC integration in the curriculum were also explored and rated from "not a challenge" to "always a challenge."

The content validity of the instrument was conducted and authenticated by an expert. Items that do not fit the Philippine context were either modified or removed. The evaluator's comments and suggestions were considered in the final draft, and the reliabilities of the instrument were also established using Cronbach's alpha (Table 1).

Means \pm standard deviation (SD) statistical analysis was used. In determining the relationship between the SHS Chemistry teachers' knowledge level, perception, integration, and challenges, a Pearson Product-Moment Correlation Coefficient was utilized where the significance level was set at $p<0.05$.

Table 1. Reliability testing of research instrument divided into five components and their corresponding Cronbach's alpha coefficient and interpretation

\begin{tabular}{lccc}
\hline \multicolumn{1}{c}{ Components } & $\begin{array}{c}\text { No. of } \\
\text { Items }\end{array}$ & $\begin{array}{c}\text { Cronbach's } \\
\text { alpha }\end{array}$ & Interpretation* \\
\hline GC knowledge test & 25 & 0.785 & Acceptable \\
Perception towards GC & 8 & 0.899 & Good \\
Level of integration of GC & 8 & 0.964 & Excellent \\
GC integration in topics & 8 & 0.910 & Excellent \\
Perception of GC & 12 & 0.943 & Excellent \\
integration as a challenge & & & \\
\hline
\end{tabular}

*Legend: Below 0.50 (unacceptable); 0.50-0.59 (poor); 0.60-0.69( questionable); 0.70-0.79 (acceptable); 0.80-0.89 (good); 0.90 and above (excellent)

\section{Qualitative Data Collection and Analysis}

The qualitative data collection and analysis were conducted independently yet concurrently with a quantitative study. This was done by two researchers who were not involved in the quantitative data collection and analysis. This is to ensure that the researchers gained in breadth and depth understanding and corroboration while they offset the biases.

A semi-structured, open-ended instrument and virtual interviews that lasted around 60 minutes were employed. Recordings and taking notes during the interviews were done with the participants' approval. Responses from 24 participants reached the saturation point, and no new themes emerged.
The researchers used the six-phase Thematic Analysis (Nowell et al., 2017). During the first step, the researchers familiarized the data by reading the participants' responses and identifying the distinct categories in the data that answer the research questions. The researchers also generated the initial codes by refining the broad categories resulting in subcategories. In this process of keeping close to the original transcripts, the terms that emerged from the participants' responses were utilized in creating codes. Then both researchers searched and reviewed the themes by re-reading the transcripts and commenting on the accuracy. The researchers developed the theme descriptions and finalized the name of each theme. Finally, the researchers identified relevant quotations from 
the responses of the participants to represent the themes. All these processes were undertaken by two researchers and validated by the third for consistency and accuracy. These were done in multiple meetings to promote trustworthiness.

To increase the rigor of the study, the researchers conducted validation and assessment through member checking (Birt et al., 2016). Returning the interview transcription and analyzing data to the participants to confirm their responses were accomplished. The transcript of the responses was resolved by reading it again to the participants and discussing its contents until both the researchers and participants reached a consensus.

\section{Convergent Data Analysis}

Findings from quantitative and qualitative phases were assessed for convergence, complementarity, or obvious contradictions after separate data analysis. Such approaches ensured that a conclusion was derived from two rigorous research methods that measure SHS Chemistry teachers' background knowledge, perceptions, integration, and perceived challenges in integrating GC. Furthermore, the convergent parallel design makes the findings more profound as the results of the quantitative and qualitative aspects of the study support each other.

\section{0 Results and Discussion}

\section{Participants Demographics}

A total of 30 SHS Chemistry teachers from private and public SHS participated in this study. Most of the participants (60\%) were female, and their ages range from 23 to 63 years old with a $33.03 \pm 9.76$. Out of 30 participants, only 16.67 percent specialized in Chemistry during their undergraduate studies, 26.67 percent of whom were Biology-majors while others were General Science, Physical Science, and Environmental Science majors. Respondents' experiences of teaching Science range from two to 33 years with an average of 7.91 years while the experiences of teaching Chemistry subject specifically range from two to 30 years with an average of 5.61 years. This implies that the age of the respondents and the years of teaching Science and Chemistry were highly distributed.

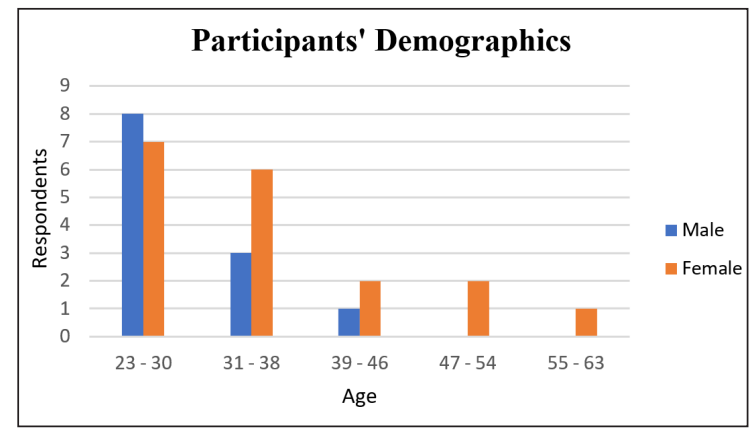

Figure 2. Participants' Demographics according to age range and proportion of male and female

Level of Knowledge of the SHS Chemistry Teachers on GC

The test outputs of the research participants were evaluated and measured using the Department of Education (DepEd) transmutation table to determine whether the score obtained after taking the test was passed or failed.

Table 2 shows that 10 percent of the participants got an outstanding rate with a percentage score of 92 and transmuted value of 95 , whereas 50 percent of participants got the average score of 11 , with a transmuted value of 71 . Therefore, the weighted mean of the knowledge level of SHS chemistry teachers is $14.53(58.13 \%)$ with a transmuted value of 74 , which can be interpreted as failed. 
Table 2. SHS Chemistry teachers' level of measured knowledge on GC

\begin{tabular}{lccccc}
\hline \multicolumn{1}{c}{ Descriptor } & $\begin{array}{c}\text { No. of } \\
\text { Participants }\end{array}$ & $\begin{array}{c}\text { Mean } \\
\text { scores }\end{array}$ & $\begin{array}{c}\text { Percentage } \\
\text { scores }\end{array}$ & $\begin{array}{c}\text { Transmuted } \\
\text { Grade }\end{array}$ & Remarks \\
\hline Outstanding & 3 & 23.00 & 92.00 & 95 & Passed \\
Very satisfactory & 1 & 20.00 & 80.00 & 88 & Passed \\
Satisfactory & 5 & 17.60 & 70.40 & 81 & Passed \\
Fairly Satisfactory & 6 & 15.50 & 62.00 & 76 & Passed \\
Did Not Meet & 15 & 11.07 & 44.28 & 71 & Failed \\
Expectations & & & & & Failed \\
Weighted mean & & $\mathbf{1 4 . 5 3}$ & $\mathbf{5 8 . 1 3 \%}$ & $\mathbf{7 4}$ & \\
\hline
\end{tabular}

The percentage of SHS Chemistry teachers who answered knowledge questions correctly is shown in Table 3. Out of 25 GC knowledge items, only questions related to the aim and importance of GC (75.83\%), GC application (74.67), and General environmental issues (65.33) were answered correctly by more than 60 percent of the participants. Fifty-three percent of the participants got the wrong answers to questions related to GC principles, tools, and concepts.

Table 3. Percentage of SHS Chemistry teachers who answered knowledge questions correctly

\begin{tabular}{lcc}
\hline \multicolumn{1}{c}{ GC Topics } & $\begin{array}{c}\text { Mean } \\
\text { frequency }\end{array}$ & $\begin{array}{c}\text { Percent } \\
(\boldsymbol{n}=\mathbf{3 0})^{*}\end{array}$ \\
\hline Aim and & 22.75 & 75.83 \\
importance of GC & & \\
Application of GC & 22.40 & 74.67 \\
GC principles & 13.33 & 44.43 \\
General & 19.60 & 65.33 \\
environmental & & \\
issues & & \\
GC tools & 15.33 & 51.10 \\
GC concepts & 13.80 & 46.00 \\
\hline
\end{tabular}

*Multiple responses allowed
Results revealed that teachers were unfamiliar with the GC principles. However, most teachers have good background knowledge on the GC aim, importance, applications, and general environmental issues. This was parallel with the quantitative and qualitative data, which led to the emergence of Theme 1: Limited Idea on Green Chemistry. The majority (19 out of 24) of the SHS Chemistry teachers revealed that they have never heard the term GC, but some attempted to explain it in a general term. They tend to associate GC concepts to Environmental Chemistry (EC) and Environmental Education (EE). They described how these concepts are related, although they have not encountered GC concepts yet. Moreover, few (5 out of 24) of the participants admitted that they have limited ideas of GC concepts. They only encountered them during their undergraduate and graduate studies. Some of the teachers' statements are as follow:

"...so this thing exist? (P2) Because this is my first time hearing about this topic - Green Chemistry..." (P6, P8, P15) 
"...I have a limited idea about this ma'am, concepts like how we can help our environment, and design processes that can minimize waste from chemical plants..." (P17)

"...I do not have much idea about this... I am only familiar about protecting the planet like preventing pollution or harmful chemicals like formaldehyde..." (P16)

\section{"...I think it is about creating chemical products} and processes that will lessen or abolish the use or production of harmful substances..." (P4)

Inferring from quantitative and qualitative results, the teachers were not fully knowledgeable of the GC concepts. The low scores in GC principlerelated questions indicate that GC foundational knowledge was not clear to participants. This implies that GC, one of the pillars of sustainable development, has not yet been introduced and incorporated into the SHS Chemistry curriculum or even in the pre-service chemistry teachers' curriculum.

Owoyemi and Adesina (2020) reported that a moderate number (52\%) of chemistry teachers had a good knowledge level with GC, and only 10.6 percent were familiar but could not explain it well. Chemistry teachers were not aware of GC due to the deficiency of seminars in addressing new topics such as GC applications and the preparatory curriculum for pre-service, which excluded GC (Hussei \& Ahmed, 2021). Matus et al. (2012) emphasized that GC is an innovative platform that is knowledge-intensive, i.e., requiring bulk quantities of information to be available before implementation.

\section{Perceptions of the SHS Chemistry Teachers towards GCE Concepts}

The data present teachers' responses on the essentiality of GC concepts in the teachinglearning process (Table 4). GC concepts have been recognized to contribute to a more sustainable environment (Mackellar et al., 2020). Although GC is not yet incorporated in the Philippine K-12 General Chemistry curriculum, teachers have already perceived such concepts as essential to the learning process. The teachers' perceptions toward GC concepts were all essential. Life cycle impacts, chemicals in the environment, and chemical hazards and exposure were perceived as the most essential (2.90 \pm 0.3$)$ while catalysis and recycling $(2.70 \pm 0.53)$ were recognized as the least essential among the eight GC concepts.

These findings were consistent with the study of Mackellar et al.'s (2020) which claimed that GC concepts like chemical hazards and exposure, chemicals in the environment, and the life cycle impact of chemicals are essential for graduates to understand. Teachers considered these concepts essential because they found a connection between their personal experiences and GC principles, either through formal or informal learning endeavors that conform to the findings of Taha et al. (2018) that teachers sometimes associate GC to Environmental Chemistry (EC). Teachers seemed knowledgeable when asked about sustainability, but their ideas were lacking. They had difficulty translating their knowledge into practices in the classroom as shown in the results when they considered catalysis and recycling reactants as the least important among the GC concepts.

Teachers' perceptions about (1) life cycle impacts, (2) chemicals in the environment, and (3) chemical hazards and exposure signify that these 
concepts are the most important in the quantitative data. These consistently confirm the teachers' perceptions during the interview. Theme 2: Green Chemistry is Essential for Environmental Protection emerged from their answers, where a majority (17 out of 24) of the teachers reasoned out that GC concepts are essential to provide awareness about chemicals, their impact on the environment and health, and potential sources of exposure. Some of the teachers' statements are as follow:

"...reactions and exposure to hazardous chemicals will affect living organisms and environment..." (P1)

"...understand the effects of chemicals in the environment..." (P3)

"...avoid mishandling of chemicals..." (P24)

"...inculcate values to learners...alternative materials that have less impact when disposed..." (P30)

In general, most participants see GC concepts as extremely important and indispensable in teaching regardless of their background and training. Teachers' experiences can be considered a contributing factor in perceiving GC as essential. Aubrecht et al. (2019) pointed out opportunities to connect General Chemistry concepts to key green and sustainable chemistry ideas. Ause (2018) also mentioned that $\mathrm{GC}$ is a way of life that is readily caught than taught. However, in Indonesia, Chemistry teachers demonstrated 47.42 percent knowledge about GCE but disagreed that the GCE principles be integrated into their curriculum (Auliah \& Mulyadi, 2018) because the concept of GCE is not familiar to them yet. Thus, the teachers should understand GCE goals to incorporate these concepts into science lessons.

Table 4. Perception of SHS Chemistry teachers towards GC concepts

\begin{tabular}{lcc}
\hline $\begin{array}{c}\text { Green Chemistry } \\
\text { Concepts }\end{array}$ & MeanSD & Interpretation \\
\hline $\begin{array}{l}\text { Reaction efficiency } \\
\text { Reaction efficiency } \\
\text { metrics }\end{array}$ & $2.87 \pm 0.34$ & Essential \\
$\begin{array}{l}\text { Reaction process } \\
\text { efficiency }\end{array}$ & $2.80 \pm 0.48$ & Essential \\
$\begin{array}{l}\text { Renewables } \\
\text { Catalysis and } \\
\text { recycling }\end{array}$ & $2.86 \pm 0.34$ & Essential \\
$\begin{array}{l}\text { Life cycle impacts } \\
\text { Chemicals in the } \\
\text { environment } \\
\text { Chemical hazards } \\
\text { and exposure }\end{array}$ & $2.90 \pm 0.53$ & Essential \\
Overall & $2.90 \pm 0.31$ & Essential \\
\hline
\end{tabular}

Legend: $1.00-1.66=$ Not important; $1.66-2.33=$ Important but not essential; $2.34-3.0=$ Essential

\section{Level of GC Integration in Teaching General Chemistry}

GC integration level in teaching General Chemistry is presented in Table 5. Life cycle impact of chemicals, Chemicals in the environment, and Chemical hazards and exposure concepts were often demonstrated, while the rest were only sometimes demonstrated. Overall, the GC integration level in General Chemistry is sometimes demonstrated ( $2.44 \pm 0.82)$.

The GC integration level in the curriculum is an educational necessity (Listyarini et al., 2019). Developing collaborative, interdisciplinary, problem-centered, and system learning in the teaching method can deepen GCE integration (Gross, 2012; I. J. Raymond \& Raymond, 2019). Furthermore, intensifying GCE in the curriculum 
builds a strong foundation towards sustainable chemical enterprise and society (Pappas et al., 2015; Kolopajlo, 2017).

Table 5. Level of GC Integration in Teaching General Chemistry

\begin{tabular}{|c|c|c|}
\hline Concepts & Mean SD & Interpretation \\
\hline Reaction efficiency & $2.37 \pm 0.85$ & $\begin{array}{c}\text { Sometimes } \\
\text { demonstrated }\end{array}$ \\
\hline Efficiency metrics & $2.30 \pm 0.84$ & $\begin{array}{c}\text { Sometimes } \\
\text { demonstrated }\end{array}$ \\
\hline Process efficiency & $2.17 \pm 0.87$ & $\begin{array}{c}\text { Sometimes } \\
\text { demonstrated }\end{array}$ \\
\hline Renewables & $2.37 \pm 1.07$ & $\begin{array}{c}\text { Sometimes } \\
\text { demonstrated }\end{array}$ \\
\hline $\begin{array}{l}\text { Catalysis and } \\
\text { recycling }\end{array}$ & $2.33 \pm 0.88$ & $\begin{array}{c}\text { Sometimes } \\
\text { demonstrated }\end{array}$ \\
\hline $\begin{array}{l}\text { Life cycle impacts } \\
\text { of chemicals }\end{array}$ & $2.60 \pm 1.07$ & $\begin{array}{c}\text { Often } \\
\text { demonstrated }\end{array}$ \\
\hline $\begin{array}{l}\text { Chemicals in the } \\
\text { environment }\end{array}$ & $2.60 \pm 1.00$ & $\begin{array}{c}\text { Often } \\
\text { demonstrated }\end{array}$ \\
\hline $\begin{array}{l}\text { Chemical hazards } \\
\text { and exposure }\end{array}$ & $2.77 \pm 1.01$ & $\begin{array}{c}\text { Often } \\
\text { demonstrated }\end{array}$ \\
\hline Overall & $2.44 \pm 0.82$ & $\begin{array}{c}\text { Sometimes } \\
\text { demonstrated }\end{array}$ \\
\hline
\end{tabular}

Legend:

1.00-1.75 - Not demonstrated;

1.76-2.50 - Sometimes demonstrated;

2.51-3.25 - Often demonstrated;

3.26-4.00 - Always demonstrated

\section{GC Integration in SHS General Chemistry Topics}

The integration of GC topics in the SHS General Chemistry curriculum is shown in Table 6. Concepts mostly integrated were Chemical hazards and exposure (93\%) and Chemicals in the environment (87\%) while Renewables (73\%) and Process efficiency (77\%) were least taught. These coincide with the findings of the study of MacKellar et al.'s (2020). Except for Chemicals in the environment and Chemical hazards and exposure, non-demonstration is quite prevalent - as it is either shown to be the highest or second highest in percentage for a given concept. Though there were teachers who tried to demonstrate some concepts in other topics, non-demonstration in the most overt Chemistry topic for a specific concept shows that teachers need to be trained on how to incorporate GC. Training can enable teachers to maximize the number of topics wherein they can integrate GC. Karpudewan and Kulandaismy (2018) support the necessity of training to educate teachers in employing GC in General Chemistry lessons.

When teachers were asked about the specific lessons they integrated with GC, Theme 3: Extent of Green Chemistry Integration emerged. Under this theme, three sub-themes surfaced. Teachers who were able to integrate GC shared specific lessons under the General Chemistry topics. During the interview, most (14 out of 24) answered concepts related to Reaction Yields, which are classified under Stoichiometry, which has the greatest total of integrations per General Chemistry topic. The next recurring specific lesson mentioned by teachers (13 out of 24) is Properties of Organic Compounds. Participants highlighted the reactivities that hydrocarbons and their derivatives exhibit. Such concept is under the topic Organic Compounds that show a high total of integration per main Chemistry topic next to Stoichiometry. This reveals that teachers who integrated these lessons are consistent with their answers in the survey questionnaire and are familiar with the rudiments of GC and know where to integrate them. With such, Sub-theme 1: Reaction Yields and Properties of Hydrocarbons as Core Specific Lessons is evident in the following statements: 


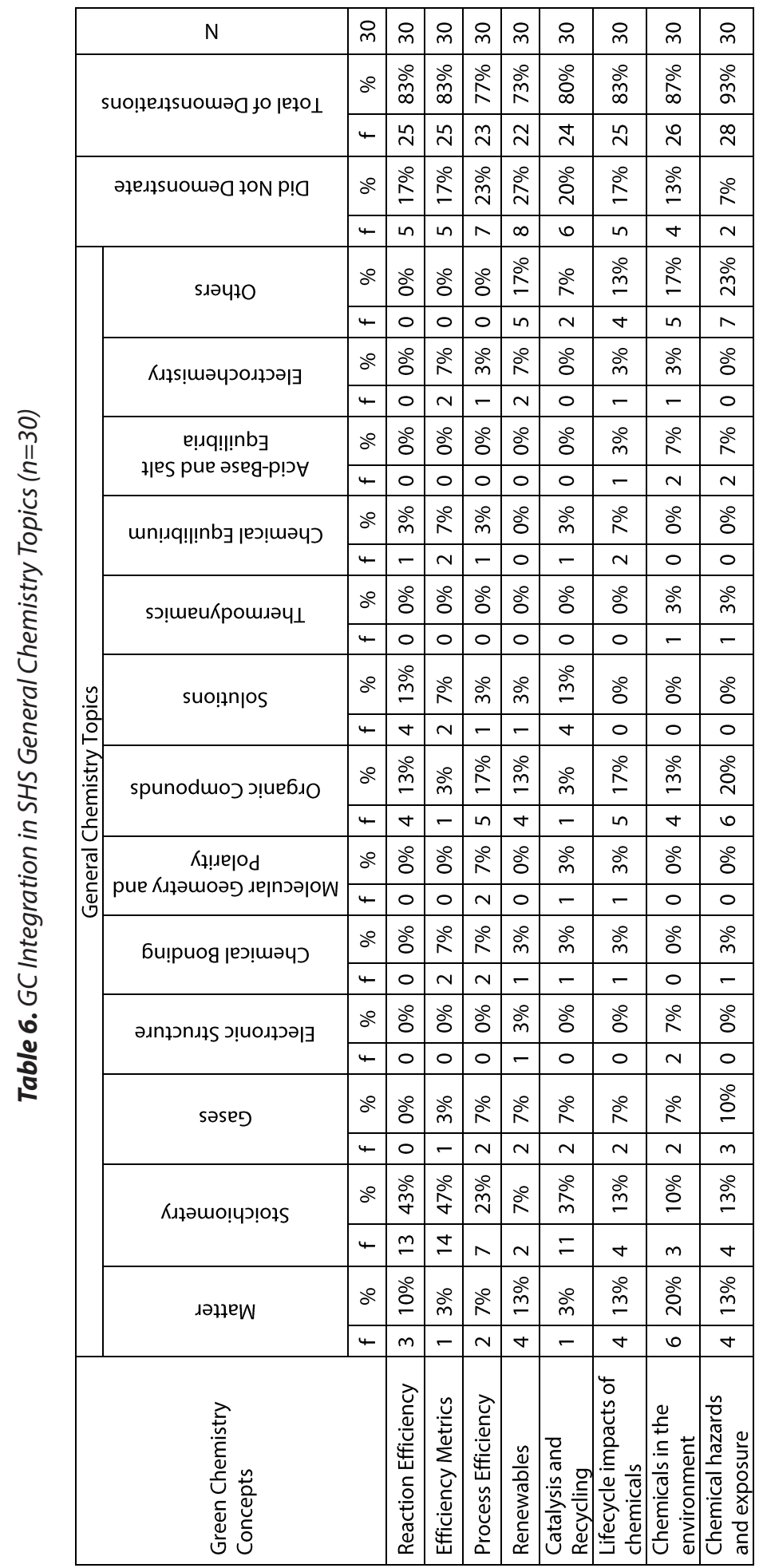


"...I integrated this concept in lessons like limiting reagents, excess reagents and percent yield..." (P14)

"...This was incorporated in lessons that involved mass-mole concept, limiting reagents, theoretical and percent yield..." (P19)

"...This was integrated with the competency wherein it is asking for students to be able to cite compounds bearing the different functional groups..." (P12)

"...I integrated this green chemistry concept in hydrocarbons, under the types of organic compounds, aromatic compounds, carbon derivatives containing oxygen..." (P17)

Teachers who did not integrate GC were asked for reasons. Their answers revealed Sub-theme 2: Non-Integration Due to Sparse Knowledge and Crowded Curriculum. Some teachers (7 out of 24) disclosed that they had little knowledge about GC. There were also others (6 out of 24) who shared integration difficulties in an already packed curriculum. Teachers conveyed the following:

"...I have very limited knowledge on Green Chemistry..." (P1)

"...I do not know that there is this such thing as Green Chemistry..." (P15)

"... There are so many competencies in General Chemistry that should be covered in our teaching. Due to limited amount of time given in a school year, we cannot cover all those competencies, so much more if we include Green Chemistry concepts as mentioned..." (P16)
"...When we teach General Chemistry, we are all after the coverage matter so much, that at times, we do not integrate these concepts. We only follow the curriculum guide, and these concepts are not being emphasized..." (P20)

Nevertheless, they recognized that they had infused GC to a meager extent, as revealed too by a Sometimes Demonstrated level of integration. This means that much work still needs to be done to integrate GC into mainstream education (Andraos \& Dicks, 2012; Haack, 2016).

Investigation about activities employed in integrating GC unfolded Sub-theme 3: Calculation and Discussions as Main Activities. Teachers (14 out of 24) shared that for concepts like Reaction Efficiency, Efficiency Metrics, and Process Efficiency, the calculation was the main educational experience given whereas, for the rest of the concepts, the main activity was discussion. Teachers (12 out of 24) admitted that such was just small inclusions during lectures. Such emanated from statements like:

"...It is more on problem-solving through calculations..." (P19)

"...I utilized problem-solving here for theoretical yield and actual yield. More on calculations really..." (P20)

...This is more on discussions because in this part I was already in a hurry to cover the topics since it was already by the end of the semester..." (P12)

"...We did not have any experiment related to this. The only thing that I have done is discussing a little bit of the concept. This is like a question-and-answer portion during the class..." (P11) 
Although teachers employed other strategies, the leading actions were mostly calculations and surface-level integration during discussions. Haack (2016) emphasized that successful implementation of GC requires diverse strategies and approaches tailored to different institutions.

\section{Perceptions of SHS Chemistry Teachers in GCE as a Challenge}

The data highlights the perceptions of SHS teachers on all challenges encountered in integrating GC in the General Chemistry instructions (Table 7). Among these challenges, two were identified to be always a challenge and both relate to teaching materials.

The lack of textbooks and the cost to develop new materials were on top of the list among the perceived challenges, and these are attributed to lack of GC emphasis and stakeholders' financial support. Meanwhile, the lack of knowledge about the content area that is found at the bottom rank $(2.57 \pm 0.86)$ is associated with a lack of resources in GC. However, the studies of MacKellar et al. (2020) and Hutchison (2019) reveal that the biggest challenge of teachers in teaching GC concepts, in addition to lack of funding, is the crowded curriculum which requires revaluation to incorporate GC. This implies that the perceived challenges faced by teachers in the Philippines in integrating GC rely more on the development and availability of learning resources like textbooks. Despite these challenges, teachers are interested in integrating GC concepts into their teachings. As Haack (2016) and Hutchison (2019) mentioned, the possibility of incorporating GC within the curriculum provides a way to solve several issues and roadblocks.
Table 7. Challenges Encountered by SHS Chemistry Teachers with regards to GC integration in the Curriculum

\begin{tabular}{|c|c|c|}
\hline Challenges & MeanSD & Interpretation \\
\hline $\begin{array}{l}\text { Lack of textbooks and } \\
\text { lecture materials }\end{array}$ & $3.50 \pm 0.86$ & $\begin{array}{l}\text { Always a } \\
\text { challenge }\end{array}$ \\
\hline $\begin{array}{l}\text { Cost to develop new } \\
\text { materials }\end{array}$ & $3.37 \pm 0.81$ & $\begin{array}{l}\text { Always a } \\
\text { challenge }\end{array}$ \\
\hline $\begin{array}{l}\text { Crowded/full } \\
\text { curriculum }\end{array}$ & $3.17 \pm 0.87$ & $\begin{array}{l}\text { Often a } \\
\text { challenge }\end{array}$ \\
\hline $\begin{array}{l}\text { Access to technical } \\
\text { resources }\end{array}$ & $3.10 \pm 0.84$ & $\begin{array}{l}\text { Often a } \\
\text { challenge }\end{array}$ \\
\hline $\begin{array}{l}\text { Lack of } \\
\text { standardization }\end{array}$ & $3.10 \pm 1.06$ & $\begin{array}{l}\text { Often a } \\
\text { challenge }\end{array}$ \\
\hline $\begin{array}{l}\text { Interdisciplinary } \\
\text { nature of the topic }\end{array}$ & $2.90 \pm 0.99$ & $\begin{array}{l}\text { Often a } \\
\text { challenge }\end{array}$ \\
\hline $\begin{array}{l}\text { Staying current on } \\
\text { technical knowledge }\end{array}$ & $2.83 \pm 0.83$ & $\begin{array}{l}\text { Often a } \\
\text { challenge }\end{array}$ \\
\hline $\begin{array}{l}\text { No felt business or } \\
\text { academic demand for } \\
\text { these skills }\end{array}$ & $2.83 \pm 1.02$ & $\begin{array}{l}\text { Often a } \\
\text { challenge }\end{array}$ \\
\hline $\begin{array}{l}\text { Identifying relevant } \\
\text { topics }\end{array}$ & $2.70 \pm 0.88$ & $\begin{array}{l}\text { Often a } \\
\text { challenge }\end{array}$ \\
\hline $\begin{array}{l}\text { Not a high priority for } \\
\text { me or my students }\end{array}$ & $2.60 \pm 1.00$ & $\begin{array}{l}\text { Often a } \\
\text { challenge }\end{array}$ \\
\hline $\begin{array}{l}\text { Lack of knowledge } \\
\text { about content area }\end{array}$ & $2.57 \pm 0.86$ & $\begin{array}{l}\text { Often a } \\
\text { challenge }\end{array}$ \\
\hline Overall & $2.97 \pm 0.91$ & $\begin{array}{l}\text { Often a } \\
\text { challenge }\end{array}$ \\
\hline
\end{tabular}

Legend:
1.00-1.75=Not $a$ challenge
$1.76-2.50=$ Sometimes $a$ challenge
2.51-3.25= Often a challenge
3.26-4.00=Always $a$ challenge

Theme 4: Barriers in Implementing Green Chemistry appeared from teachers' perceptions on GC integration which comprises three subthemes: lack of expertise, non-inclusion of GC in curriculum, and insufficient resources. Teachers (17 
out of 24) admitted that they lacked knowledge in the content area and fell behind staying current on technical knowledge. These items were perceived as often a challenge. This is expressed in Sub-theme 1: Lack of Expertise. Teachers verbalized that:

"...Most of the teachers didn't have the content on Green Chemistry Education concepts, wherein they make use of a strategy that only the students will work, but students cannot process it well..." (P14)

"...There's no specific topic or subject about green chemistry; not part in the curriculum especially in the basic education..." (P18)

"...The lack of experience on GCE leads to the articulation on "spending so much time to stay current about technical knowledge..." (P20)

"...There is need to master or familiarize the mathematical skill or stoichiometric skill and the concept skill..." (P13)

The challenges experienced by teachers in integrating GC are linked to insufficiency of GC content knowledge and the need to update technical knowledge like conceptual skill familiarization. These challenges are shared among Canadian educators highlighting the need for relevant and updated technical resources (PłotkaWasylka et al., 2018).

Sub-theme 2: Non-inclusion of GC in the Curriculum revealed teachers' (17 out of 24) sensitivity on the following GC integration challenges like standardization, topic relevance, interdisciplinary nature, technical resources, priority in teaching, and academic skills. These items were perceived as often a challenge. Meanwhile, they narrated their experiences:
"...There are a lot of learning competencies in given a short period ..." (P11)

"...Due to the congested curriculum; not a priority of DepEd CG..." (P20)

"...No concrete guideline in standardizing Green Chemistry's content..." (P16)

"...We cannot deepen the concepts because there are still other "main" concepts to be taught aside from GC concepts..." (P19)

Teachers' views on curriculum congestion and lack of integration standardization of GC concepts in the SHS Chemistry curriculum contribute to other challenges they experienced. However, GC integration challenges should not be taken negatively since Green Chemistry is not meant to replace the existing curriculum. Instead, it will be taught in a new way - that is, incorporating key concepts into the curriculum to make chemistry inherently 'green' (Kitchens et al., 2006).

Sub-theme 3: Insufficient Resources unveiled teachers' lack of textbooks and cost to develop materials to be always a challenge in teaching GC concepts. Teachers (17 out of 24 ) have expressed:

"...There is no book intended for Green Chemistry..." (P18)

"... I use published GC articles; I think it's better to have a book on it but it's too expensive..." (P10)

"...Very limited resources in teaching GC and there's a need for continuous internet surfing which is costly..." (P11)

"... Having a new material that costly and time consuming..." (P14) 
GC integration difficulties of teachers are generally due to the unavailability of learning materials and the lack of funding to support its development which was emphasized in the study of MacKellar et al. (2020).

\section{Correlation between Knowledge, Perceptions, and Level of Integration}

Table 8 shows the relationships between knowledge, perceptions, and level of GC integration. There was a moderate, positive correlation between teachers' knowledge and perception of GC, which was statistically significant ( $r=0.41, n=30, p=0.03$, two-tailed). This suggests that the teachers' knowledge of General Chemistry affects their perceptions to a moderate extent. The moderate, positive correlation further implies that although the teachers' background on GC has a bearing on their $\mathrm{GC}$ perceptions, other factors like their exposure to Environmental Science influence their ideas about how essential these concepts are.

As the term "green chemistry" has not always been used in the industry, it is with the educational sector. However, concepts like the dangerous impacts of chemicals and some "green methods" go a long way back before any cognizance of environmental impacts became a trend (Andraos \& Dicks, 2012). Therefore, most teachers might not have encountered the term "green chemistry" and, in general, did not meet the 75 percent DepEd standard when it comes to GC knowledge, yet, they might have accumulated the importance of sustainability in some other ways which added to their belief in sustainability.

As the moderate impact of GC knowledge on teachers' perceptions has been established, so it is imperative to strengthen teachers' GC perceptions with an ample number of related training and seminars that will deepen their knowledge. This will reinforce and sharpen their point of view on GC, which could help them integrate these concepts with ease into their lessons. Karpudewan and Kulandaismy (2018) emphasized that it is necessary to expose students to GC at the secondary level and that teachers are the determinant in finding ways for having GC in education. It would be difficult to expect the learners to know GC if their teacher does not understand it first-hand (Auliah \& Mulyadi, 2018). Therefore, the teachers should first be equipped before such principles can be educated in the next generation of the workforce (Eze, 2015).

Table 8. Correlations between knowledge, perception, and level of integration

\begin{tabular}{lllll}
\hline & & Knowledge & Perception & Level of Integration \\
\hline \multirow{4}{*}{ Knowledge } & Pearson Correlation & 1 & $0.41^{*}$ & 0.21 \\
& Significance (2-tailed) & $\cdot$ & 0.03 & 0.26 \\
& $\mathrm{n}$ & 30 & 30 & 30 \\
\multirow{3}{*}{ Perception } & Pearson Correlation & $0.41^{*}$ & 1 & 0.21 \\
& Significance (2-tailed) & 0.03 & $\cdot$ & 0.25 \\
& $\mathrm{n}$ & 30 & 30 & 30 \\
Level of Integration & Pearson Correlation & 0.21 & 0.21 & 1 \\
& Significance (2-tailed) & 0.26 & 0.25 &. \\
& $\mathrm{n}$ & 30 & 30 & 30 \\
\hline
\end{tabular}

${ }^{*}$ Correlation is significant at the 0.05 level (2-tailed) 
The correlation between teachers' knowledge and their level of integration of GC was statistically not significant ( $r=0.21, n=30, p=0.26$, two-tailed). This means that there is no correlation between teachers' knowledge of GC and their level of integration of these concepts in their General Chemistry classes.

Similarly, the correlation between teachers' perceptions of GC and their integration level of such concepts was statistically insignificant $(r=0.21$, $N=30, p=0.25$, two-tailed). This indicates that there is no correlation between teachers' perceptions of GC and their level of integration.

These results suggest that teachers'knowledge and perceptions of these principles do not affect their integration level in their Chemistry classes. Teachers might know GC and find these ideas essential, but their GC perspective is not always expressed in their classroom teaching. This reveals that there are other elements to be considered which influence the degree of integration other than the teachers' knowledge and perceptions. These factors could be an insignificant emphasis of GC in the General Chemistry curriculum, zero GC training.

GC's insignificant emphasis on the General Chemistry curriculum conveys that curriculum enrichment should be done. Ajewole et al. (2009), as cited by Eze (2015), expressed that curriculum enrichment is upgrading the quality of curriculum contents to make the educational system more relevant and responsive. Therefore, enrichment of the present curriculum with GC will establish the necessity of Green Chemistry in the teachers' practices of chemistry teaching. In turn, the teaching of GC will equip students to make wise decisions on matters that have environmental impact (Gabucan \& Sanchez, 2021) and produce people who can create and utilize procedures that diminish pollution (Ballard \& Mooring, 2020).

\section{Complementarity of Quantitative and Qualitative Findings}

Using convergent parallel mixed methods added depth and meaning to the results and interpretation of this study as both quantitative and qualitative methodologies have outcomes that complemented each other.With this, theresearchers got a wider and intensive comprehension of the status of Green Chemistry Education among the SHS Chemistry teachers. Each methodology elucidated, and thus, illuminated certain gaps in the opposite methodology. The complementarity of results strengthens the validity and reliability of this research endeavor.

\subsection{Conclusion and Recommendations}

This study is the first of its kind to explore teachers' knowledge, perceptions, and integration of GC in the country. The quantitative and qualitative results complemented each other. Thereby, the validity and reliability of the findings were intensified. Teachers perceived the importance of GC in the curriculum, and they were able to integrate GC, but the scope of their integration is a mere scratch of a deep pro-active pedagogical approach that aims to highlight sustainability practices. Teachers' knowledge and perceptions of GC do not have a bearing on their level of integration since there are factors that hinder their assimilation of such concepts into their classes. Having a moderate impact on teachers' perceptions, SHS Chemistry teachers' knowledge about GCE must be enhanced through training, seminars, and post-graduate studies. Provision of resource materials and review of the curriculum are important to drive teachers in integrating GC. The inclusion of GCE in the basic and higher education science curricula should be implemented so that responsibility towards the environment is inculcated among the students. 


\section{References}

Ajewole G.A., Nzewi U., \& Aganga A.B. (2009). Curriculum enrichment of science, technology and mathematics education as a basis for developing entrepreneurship skills. In N. A. Udofia (Ed.). Developing entrepreneurial skills through STM education : 50th Annual Conference, 2009 (pp. 26-30). HEBN Publishers

Anastas, P. \& Eghbali, N. (2010). Green chemistry: Principles and practice. Chemical Society Reviews, 39(1), 301-312. https://doi.org/ 10.1039/b918763b.

Anastas, P.T. \& Warner, J.C. (1998). Green chemistry: Theory and practice. Oxford University Press.

Andraos, J. \& Dicks, A. (2012). Green chemistry in higher education: A review of effective practices. Chemistry Education Research and Practice, 13, 69-79. https://doi.org/10.1039/ C1RP90065J

Aubrecht, K.B., Bourgeois, M., Brush, E.J., Mackellar, J., \& Wissinger, J.E. (2019). Integrating green chemistry in the curriculum: Building student skills in systems thinking, safety, and sustainability. Journal of Chemical Education, 96(12) 2872-2880 https://doi.org/10.1021/ acs.jchemed.9b00354

Auliah, A. \& Mulyadi, M. (2018). Indonesian teachers' perceptions on green chemistry principles: $\mathrm{A}$ case study of a chemical analyst vocational school. Journal of Physics : Conference series, 1028, 012942. https://doi.org/10.1088/17426596/1028/1/012042.

Ause, R. (2018). Green chemistry in secondary schools. Physical Sciences Reviews, 4(2). https://doi.org/10.1515/psr-2018-0081
Ballard, J., \& Mooring, S.R. (2021). Cleaning our world through green chemistry: Introducing high school students to the principles of green chemistry using a case-based learning module. Journal of Chemical Education, 98(4), 1290-1295. https://dx.doi.org/10.1021/acs. jchemed.9b00312

Birt, L., Scott, S., Cavers, D., Campbell, C., \& Walter, F. (2016). Member checking: A tool to enhance trustworthiness or merely a nod to validation? Qualitative Health Research, 26(13),1802-1811. https://doi.org/10.1177/1049732316654870

Cann, M. \& Dickneider, T. (2004). Infusing the green chemistry curriculum with green chemistry using real-world examples, web modules, and atom economy in organic chemistry courses. Journal of Chemical Education, 81(7), 977-980. https://doi.org/10.1021/ed081p977

Collins T. (1995). Introducing green chemistry in teaching and research. Journal of Chemical Education, 72(11), 965-966. https://doi. org/10.1021/ed072p965

Creswell, J.W., \& Plano-Clark, V.L. (2011). Designing and conducting mixed methods research (2nd ed.). Sage Publications.

Eze, C. (2015, May). Enriching chemistry teacher education curriculum through integration of green chemistry principles. Knowledge Review 31(1), https://www.globalacademicgroup. com/journals/knowledge\%20review/ Chikwere.pdf

Gabucan, J., \& Sanchez, J.M. (2021). Strategic intervention material (SIM)-based instruction in teaching global warming in 9th grade science. Formatif: Jurnal Ilmiah Pendidikan MIPA, 11(1), 15-24. http://dx.doi.org/10.30998/ formatif.v1 1 i1.6448 
Gross, E.M. (2012). Green chemistry and sustainability: An undergraduate course for science and nonscience majors. Journal of Chemistry Education, 90(4), 429-431. https:// doi.org/10.1021/ed200756z

Haack, J. (2016). Green chemistry education: 25 years of progress and 25 years ahead. ACS Sustainable Chemistry and Engineering, 4(11), 5889-5896. https://doi.org/ 10.1021/ acssuschemeng.6b02069

Hussei, A.A., \& Ahmed, S. D. (2021). Awareness of the principles of green chemistry among middle school teachers. Turkish Journal of Computer and Mathematics Education, 12(7), 475-483. https://doi.org/10.17762/turcomat. v12i7.2607

Hutchison, J.E. (2019). Systems thinking and green chemistry: Powerful levers for curricular change and adoption. Journal of Chemical Education, 96(12), 2777-2783. https://doi. org/10.1021/acs.jchemed.9b00334

Karpudewan, M., \& Kulandaismy, Y. (2018). Malaysian teachers' insights into implementing green chemistry experiments in secondary schools. Current Opinion in Green and Sustainable Chemistry, 13, 113-117. https://doi.org/10.1016/j.cogsc.2018.06.015

Kitchens, C., Charney, R., Naistat, D., Farrugia, J., Clarens, A., O'Neil, A., Lisowski, C., \& Braun, B. (2006). Completing our education. Green chemistry in the curriculum. Journal of Chemical Education, 83(8), 1126. https://doi. org/10.1021/ed083p1126

Kolopajlo, L. (2017). Green chemistry pedagogy. Physical Sciences Reviews, 2(2), 1-25. https:// doi.org/10.1515/psr-2016-0076
Linkwitz, M. \& Eilks, I. (2020). Greening the senior high school chemistry curriculum: An action research initiative. In S. O. Obare, C. H. Middlecamp, \& K. E. Peterman (Eds.). Chemistry education for a sustainable society volume 1: High school, outreach, \& global perspectives (pp: 55-68). ACS Publications. https://doi.org/10.1021/bk-2020-1344.ch005

Listyarini, R. V., Pamenang, F. D. N., Harta, J., Wijayanti, L. W., Asy'ari, M., \& Lee, W. (2019). The integration of green chemistry principles into small scale chemistry practicum for senior high school students. Indonesian Journal of Science Education, 8(3), 371-378. https://doi.org/10.15294/jpii.v8i3.19250

MacKellar, J.J., Constable, D.J., Kirchhoff, M.M., Hutchison, J.E., \& Beckman, E. (2020). Toward a green and sustainable chemistry education road map. Journal of Chemical Education, 97(8), 2104-2113. https://doi.org/10.1021/ acs.jchemed.0c00288

Matus, K.J., Clark, W.C., Anastas, P.T., \& Zimmerman, J.B. (2012). Barriers to the implementation of green chemistry in the United States. Environmental Science \& Technology, 46(20), 10892-10899. http://dx.doi.org/10.1021/ es3021777

Nersesian, E., Spryszynski, A., \& Lee, M.J. (2019). Integration of virtual reality in secondary STEM education. IEEE Integrated STEM Education Conference (ISEC). https://doi.org/10.1109/ ISECon.2019.8882070.

Nowell, L.S., Norris, J.M., White, D.E., \& Moules, N.J. (2017). Thematic analysis: Striving to meet the trustworthiness criteria. International Journal of Qualitative Methods, 16, 1-13. https://doi. org/10.1177/1609406917733847 
Owoyemi, T.E., \& Adesina, A.S. (2020). Pre-service and in-service chemistry teachers' knowledge and attitude to green chemistry in Lagos State, Nigeria. Journal of Curriculum and Instruction, 13(1), 22-33. file:///C:/Users/imcmain/Downloads/91-Article\%20Text-169-110-20200722.pdf

Paderes, N.M. (2018). Green chemistry perspective among STEM 12 senior high school students. IAMURE International Journal of Ecology and Conservation, 24(1). http://ejournals.ph/form/ cite.php?id=13993

Pappas, E., Pappas, J., \& Sweeney, D. (2015). Walking the walk: Conceptual foundations of the sustainable personality. Journal of Cleaner Production, 86, 323-334. https://doi. org/10.1016/j.jclepro.2014.08.077

Płotka-Wasylka, J., Kurowska-Susdorf, A., Sajid, M., Namieśnik, J., \& Tobiszewski, M. (2018). Green chemistry in higher education: State of the art, challenges, and future trends. ChemSusChem, 11, 2845-2858. https//:doi. org/10.1002/cssc.201801109

Raymond, I.J., \& Raymond, C.M. (2019). Positive psychology perspectives on social values and their application to intentionally delivered sustainability interventions. Sustainability Science, 14, 1381-1393. https://doi. org/10.1007/s11625-019-00705-9

Santos, R.G. \& Guidote, A.M., Jr. (2015). The green chemistry and Filipino approach to high school experiments in Saint Paul College Pasig. International Journal of Curriculum and Instruction, 7(2), 51-57. https://www. researchgate.net/publication/303686287_ The_green_chemistry_and_Filipino_ approach_to_high_school_experiments_in_ Saint_Paul_College_Pasig

Tabotabo-Picardal, M. \& Paño, J.D. (2018). Facilitating instruction of central dogma of molecular biology through contextualization. Journal of Teacher Education and Research, 13(2), 118-132. https://doi.org/10.5958/24541664.2018.00012.5

Taha, H., Suppiah, V., Khoo, Y., Yahaya, A., Lee, T., \& Muhamad, D. M. (2018). Impact of student initiated green chemistry experiment on their knowledge, awareness and practices of environmental sustainability. Journal of Physics: Conference Series, 1156, 012022 https://doi.org/10.1088/17426596/1156/1/012022.

Twelve more green chemistry principles. (2001). Green Chemistry, 3(6), G73. https://doi. org/10.1039/B110187K

Wissinger, J.E., Knutson, C.M., \& Javner, C.H. (2020). Designing impactful green and sustainable chemistry workshops for high school teachers. In S. O. Obare, C. H. Middlecamp, \& K. E. Peterman (Eds.). Chemistry education for a sustainable society volume 1: High school, outreach, \& global perspectives (pp. 1-14). ACS Publications. https://doi.org/10.1021/bk2020-1344.ch001

Zuin, V.G., Eilks, I., Elschami, M., \& Kümmerer, K. (2021). Education in green chemistry and in sustainable chemistry: Perspectives towards sustainability. Green Chemistry, 23(4),15941608. https://doi.org/10.1039/D0GC03313H 